\title{
Trypsin-induced proteome alteration during cell subculture in mammalian cells
}

\author{
Hsiang-Ling Huang1', Hsiang-Wei Hsing1', Tzu-Chia Lai1 , Yi-Wen Chen'1, Tian-Ren Lee1, Hsin-Tsu Chan', Ping-

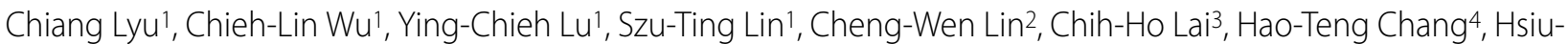 \\ Chuan Chou*5 and Hong-Lin Chan*1
}

\begin{abstract}
Background: It is essential to subculture the cells once cultured cells reach confluence. For this, trypsin is frequently applied to dissociate adhesive cells from the substratum. However, due to the proteolytic activity of trypsin, cell surface proteins are often cleaved, which leads to dysregulation of the cell functions.

Methods: In this study, a triplicate 2D-DIGE strategy has been performed to monitor trypsin-induced proteome alterations. The differentially expressed spots were identified by MALDI-TOF MS and validated by immunoblotting.

Results: 36 proteins are found to be differentially expressed in cells treated with trypsin, and proteins that are known to regulate cell metabolism, growth regulation, mitochondrial electron transportation and cell adhesion are downregulated and proteins that regulate cell apoptosis are up-regulated after trypsin treatment. Further study shows that bcl-2 is down-regulated, p53 and p21 are both up-regulated after trypsinization.
\end{abstract}

Conclusions: In summary, this is the first report that uses the proteomic approach to thoroughly study trypsininduced cell physiological changes and provides researchers in carrying out their experimental design.

\section{Background}

Plasma membrane proteins are responsible for a wide variety of functions essential to maintaining normal physiological activities. For example, when EGF receptor families, a group of proteins located in the plasma membrane that act as growth receptors, transmit external signals into the cell interior, cell's physiological activities are often altered in response to external signals. In addition, adhesive proteins, such as the cadherin families [1] in the cell membrane, provide anchors to link cytoskeleton proteins with extracellular matrix to regulate cell migration and cell adhesion. The dysregulations of membrane proteins cause numerous diseases such as during tumorigenesis, malignant transformation of epithelial cells frequently attends with loss of E-cadherin expression and induction of expression of mesenchymal membrane pro-

*Correspondence: showchuan@yahoo.com.tw, hlchan@life.nthu.edu.tw 5 Department of Applied Science, National Hsinchu University of Education, Hsinchu, Taiwan

${ }^{1}$ Institute of Bioinformatics and Structural Biology \& Department of Life Sciences, National Tsing Hua University, Hsinchu, Taiwan

Full list of author information is available at the end of the article teins like $\mathrm{N}$-cadherin [2,3]. Moreover, mutations of ErbB2 receptors lead to the occurrence of gastric cancer [4] and hepatocellular cancer [5].

Two-dimensional gel electrophoresis (2-DE) has been widely used for profiling cellular proteins and some of the nonionic and zwitterionic detergents such as thiourea and CHAPS have been introduced to increase the solubility of the proteins. In addition, a significant improvement of gel-based analysis of protein quantifications and detections is the introduction of 2D-DIGE. 2D-DIGE is able to co-detect numerous samples in the same 2-DE to minimize gel-to-gel variation and compare the protein features across different gels by means of an internal fluorescent standard. This innovative technology relies on the pre-labeling of protein samples before electrophoresis with fluorescent dyes $\mathrm{Cy} 2, \mathrm{Cy} 3$ and $\mathrm{Cy} 5$ each exhibiting a distinct fluorescent wavelength to allow multiple experimental samples to include an internal standard. Thus, the samples can be simultaneously separated in one gel. The internal standard, which is a pool of an equal amount of the experimental protein samples, can facilitate the data accuracy in normalization and increase sta- 
tistical confidence in relative quantitation across gels [610].

The primary step in adherent-cell-subculture is to detach cells from the substratum as the cells reach high confluence. Trypsin is often applied for this purpose. Cells are subsequently subdivided and reseeded into fresh cultures. However, the proteolytic activity of trypsin may harm cells by cleaving the cell surface growth factor receptors or membrane proteins. Hence, this study describes a 2D-DIGE strategy to perform cellular proteins labeling for the monitoring of trypsin-induced proteome alterations in mammalian cells.

\section{Materials and Methods}

\section{Chemicals and Reagents}

Generic chemicals were purchased from Sigma-Aldrich (St. Louis, USA), while reagents for 2D-DIGE were purchased from GE Healthcare (Uppsala, Sweden). All primary antibodies were purchased from Abcam (Cambridge, UK) and secondary antibodies were purchased from GE Healthcare (Uppsala, Sweden). All chemicals and biochemicals used were of analytical grade. Fetal calf serum (FCS), antibiotics and trypsin were purchased from Invitrogen (all from Gibco-Invitrogen Corp., UK).

\section{Cell lines and cell cultures}

The breast cancer cell line MCF-7 and cervical cancer cell line Hela were both purchased from American Type Culture Collection (ATCC), Manassas, VA. Both cell lines were maintained in Dulbecco's modified Eagle's medium (DMEM) supplemented with $10 \%(\mathrm{v} / \mathrm{v})$ fetal calf serum (FCS), L-glutamine $(2 \mathrm{mM})$, streptomycin $(100 \mu \mathrm{g} / \mathrm{mL})$, and penicillin $(100 \mathrm{IU} / \mathrm{mL}$ ) (all from Gibco-Invitrogen Corp., UK). Non-enzymatical cell dissociation solution was purchased from Sigma and 0.05\% EDTA-Trypsin was purchased from Gibco-Invitrogen Corp. Cells were incubated in a humidified incubator at $37^{\circ} \mathrm{C}$ and $5 \% \mathrm{CO}_{2}$.

\section{Cell trypsinization and CyDye labeling for 2D-DIGE analysis} The cellular protein labeling strategy was performed according to the protocol described previously with some modifications [9]. Once $90 \%$ of confluence is reached, MCF-7 and Hela cells were washed with Hank's balance salt solution (HBSS), detached with non-enzymatical cell dissociation solution and centrifuged for $5 \mathrm{~min}$ at $800 \mathrm{xg}$. The cell pellet was firstly washed with $1 \mathrm{ml}$ ice cold HBSS pH8.3, and then resuspended in $200 \mu \mathrm{l}$ of 2-DE lysis buffer containing $4 \% \mathrm{w} / \mathrm{v}$ CHAPS, $7 \mathrm{M}$ urea, $2 \mathrm{M}$ thiourea, $10 \mathrm{mM}$ Tris- $\mathrm{HCl}, \mathrm{pH} 8.3$ and $1 \mathrm{mM}$ EDTA. Before performing 2D-DIGE, protein samples were labeled with $\mathrm{N}$ hydroxy succinimidyl ester-derivatives of the cyanine dyes Cy2, Cy3 and Cy5. Briefly, $150 \mu \mathrm{g}$ of protein sample was minimally labeled with 375 pmol of either Cy3 or Cy5 for comparison on the same 2-DE. To facilitate image matching and cross-gel statistical comparison, a pool of all samples was also prepared and labeled with Cy2 at a molar ratio of $2.5 \mathrm{pmol}$ Cy2 per $\mu \mathrm{g}$ of protein as an internal standard for all gels. Thus, the triplicate samples and the internal standard could be run and quantify on multiple 2-DE. The labeling reactions were performed in the dark on ice for $30 \mathrm{~min}$ and then quenched with a 20 -fold molar ratio excess of free L-lysine to dye for $10 \mathrm{~min}$. The differentially Cy3- and Cy5-labeled samples were then mixed with the Cy2-labeled internal standard and reduced with dithiothreitol for $10 \mathrm{~min}$. IPG buffer, pH310 nonlinear $(2 \%(\mathrm{v} / \mathrm{v})$, GE Healthcare) was added and the final volume was adjusted to $450 \mu \mathrm{l}$ with 2D-lysis buffer for rehydration. The rehydration process was performed with immobilized non-linear $\mathrm{pH}$ gradient (IPG) strips $(\mathrm{pH} 3-10,24 \mathrm{~cm})$ which were later rehydrated by CyDyelabeled samples in the dark at room temperature overnight (at least 12 hours). Isoelectric focusing was then performed using a Multiphor II apparatus (GE Healthcare) for a total of $62.5 \mathrm{kV}-\mathrm{h}$ at $20^{\circ} \mathrm{C}$. Strips were equilibrated in $6 \mathrm{M}$ urea, $30 \%(\mathrm{v} / \mathrm{v})$ glycerol, $1 \%$ SDS (w/v), 100 $\mathrm{mM}$ Tris- $\mathrm{HCl}$ (pH8.8), $65 \mathrm{mM}$ dithiothreitol for $15 \mathrm{~min}$ and then in the same buffer containing $240 \mathrm{mM}$ iodoacetamide for another $15 \mathrm{~min}$. The equilibrated IPG strips were transferred onto $26 \times 20-\mathrm{cm} 12.5 \%$ polyacrylamide gels casted between low fluorescent glass plates. The strips were overlaid with $0.5 \%(\mathrm{w} / \mathrm{v})$ low melting point agarose in a running buffer containing bromophenol blue. The gels were run in an Ettan Twelve gel tank (GE Healthcare) at 4 Watt per gel at $10^{\circ} \mathrm{C}$ until the dye front had completely run off the bottom of the gels. Afterward, the fluorescence 2-DE was scanned directly between the low fluorescent glass plates using an Ettan DIGE Imager (GE Healthcare). This imager is a charge-coupled devicebased instrument that enables scanning at different wavelengths for Cy2-, Cy3-, and Cy5-labeled samples. Gel analysis was performed using DeCyder 2-D Differential Analysis Software v7.0 (GE Healthcare) to co-detect, normalize and quantify the protein features in the images. Features detected from non-protein sources (e.g. dust particles and dirty backgrounds) were filtered out. Spots displaying a $\times 1.5$ average-fold increase or decrease in abundance with a p-value $<0.05$ were selected for protein identification.

\section{Protein staining}

Colloidal coomassie blue G-250 staining was used to visualize Cy dye-labeled protein features in 2-DE according the protocol described in [11-13]. Briefly, bonded gels were fixed in $30 \% \mathrm{v} / \mathrm{v}$ ethanol, $2 \% \mathrm{v} / \mathrm{v}$ phosphoric acid overnight, washed three times (30 min each) with $\mathrm{ddH}_{2} \mathrm{O}$ 
and then incubated in $34 \% \mathrm{v} / \mathrm{v}$ methanol, $17 \% \mathrm{w} / \mathrm{v}$ ammonium sulphate, $3 \% \mathrm{v} / \mathrm{v}$ phosphoric acid for $1 \mathrm{hr}$., prior to adding $0.5 \mathrm{~g} /$ liter coomassie blue G-250. The gels were then left to stain for 5-7 days. No destaining step was required. The stained gels were then imaged on an ImageScanner III densitometer (GE Healthcare), which processed the gel images as .tif files.

\section{In-gel digestion}

Excised post-stained gel pieces were washed three times with $50 \%$ acetonitrile, dried in a SpeedVac for $20 \mathrm{~min}$., reduced with $10 \mathrm{mM}$ dithiothreitol in $5 \mathrm{mM}$ ammonium bicarbonate $\mathrm{pH} 8.0$ (AmBic) for $45 \mathrm{~min}$ at $50^{\circ} \mathrm{C}$ and then alkylated with $50 \mathrm{mM}$ iodoacetamide in $5 \mathrm{mM}$ AmBic for $1 \mathrm{hr}$. at room temperature in the dark. Gel pieces were then washed three times in $50 \%$ acetonitrile and vacuumdried before reswelling with $50 \mathrm{ng}$ of modified trypsin (Promega) in $5 \mathrm{mM}$ AmBic. The pieces were then overlaid with $10 \mu \mathrm{l}$ of $5 \mathrm{mM}$ AmBic and trypsinized for $16 \mathrm{hr}$ at $37^{\circ} \mathrm{C}$. Supernatants were collected, peptides were further extracted twice with $5 \%$ trifluoroacetic acid in 50\% acetonitrile and the supernatants pooled. Peptide extracts were vacuum-dried, resuspended in $5 \mu \mathrm{l} \mathrm{dd}_{2} \mathrm{O}$ and stored at $-20^{\circ} \mathrm{C}$ prior to $\mathrm{MS}$ analysis.

\section{Protein identification by MALDI-TOF MS}

MALDI-TOF MS with generated peptide mass fingerprinting was used for protein identification. Briefly, $0.5 \mu \mathrm{l}$ of tryptic digested protein sample was mixed with $0.5 \mu \mathrm{l}$ of matrix solution containing $\alpha$-cyano-4-hydroxycinammic acid at a concentration of $1 \mathrm{mg}$ in $1 \mathrm{ml}$ of $50 \%$ acetonitrile $(\mathrm{v} / \mathrm{v}) / 0.1 \%$ trifluoroacetic acid $(\mathrm{v} / \mathrm{v})$, spotted onto a anchorchip target plate (Bruker Daltonics) and dried. The peptide mass fingerprints were acquired using an Autoflex III mass spectrometer (Bruker Daltonics) in reflector mode. The spectrometer was calibrated with a peptide calibration standard (Bruker Daltonics) and internal calibration was performed using trypsin autolysis peaks at $m / z 842.51$ and $m / z 2211.10$. Peaks in the mass range $m / z 800-3000$ were used to generate a peptide mass fingerprint that was searched against the updated SwissProt/TrEMBL database (v56.5) with 402482 entries on December 19, 2008 using Mascot software v2.2.04 (Matrix Science, London, UK). The parameters used for the search were: Homo sapiens; tryptic digest with a maximum of 1 missed cleavage; carbamidomethylation of cysteine, partial protein N-terminal acetylation, partial methionine oxidation and partial modification of glutamine to pyroglutamate and a mass tolerance of $50 \mathrm{ppm}$. Identification was accepted based on significant MASCOT Mowse scores $(p<0.05)$.

\section{Immunoblotting}

Immunoblotting was used to validate the differential expression of mass spectrometry identified proteins. Membrane fraction extracts were briefly lysed with 2-DE lysis buffer prior to protein quantification with Coomassie Protein Assay Reagent (BioRad). $30 \mu \mathrm{g}$ of protein samples were diluted in Laemmli sample buffer (final concentrations: $50 \mathrm{mM}$ Tris $\mathrm{pH}$ 6.8, 10\% (v/v) glycerol, $2 \%$ SDS (w/v), 0.01\% (w/v) bromophenol blue) and separated by $1 \mathrm{D}-\mathrm{SDS}-\mathrm{PAGE}$ according to standard procedures. After electroblotting of separated proteins onto $0.45 \mu \mathrm{m}$ Immobilon P membranes (Millipore), the membranes were blocked with $5 \% \mathrm{w} / \mathrm{v}$ skimmed milk in TBST (50 mM Tris pH 8.0, $150 \mathrm{mM} \mathrm{NaCl}$ and 0.1\% Tween-20 $(\mathrm{v} / \mathrm{v}))$ for $1 \mathrm{hr}$. Membranes were then incubated in primary antibody solution in TBS-T containing $0.02 \%(\mathrm{w} / \mathrm{v})$ sodium azide for $2 \mathrm{hrs}$. Membranes were washed in TBS$\mathrm{T}(3 \times 10 \mathrm{~min})$ and then probed with the appropriate horseradish peroxidase-coupled secondary antibody (GE Healthcare). After further washes in TBS-T, immunoprobed proteins were visualized using an enhanced chemiluminescence method (Visual Protein Co.).

\section{Results \\ 2D-DIGE analysis of the trypsin-induced differentially expressed proteins}

To identify the altered abundance of proteins and relate them to trypsinization, MCF-7 cells were washed with HBSS followed by dissociating cells from substratum with non-enzymatic cell dissociation solution for $15 \mathrm{~min}$ or $0.05 \%$ trypsin-EDTA for $10 \mathrm{~min}$ after cells reach approximately $90 \%$ confluence. The dissociation time for attached MCF-7 cells were optimized by examined the number of adherent cells after treatment of non-enzymatic cell dissociation solution or $0.05 \%$ trypsin-EDTA (Figure 1A). Trypsin-digested MCF-7 cells were then either directly neutralized with $10 \%$ FCS followed by performed cell lysis or reseeded onto cell culture plates to recover for $8 \mathrm{hr}$ and $24 \mathrm{hr}$ before being dissociated with non-enzymatic cell dissociation solution for cell lysis. Subsequently, the lysed cells from each condition were minimally labeled with Cy3 or Cy 5 dye and distributed to each gel. A pool of all samples was also prepared for labeling with Cy2 as an internal standard to run on all gels to facilitate image matching across gels. Thus, the triplicate samples resolved in different gels can be quantitatively analyzed by means of the internal standard on multiple 2DE. The dissociation and protein labeling procedures are described in Figure 1B and in the Materials \& Methods section. After resolving protein samples with 2D-DIGE technique, the DeCyder image analysis software indicated 
A

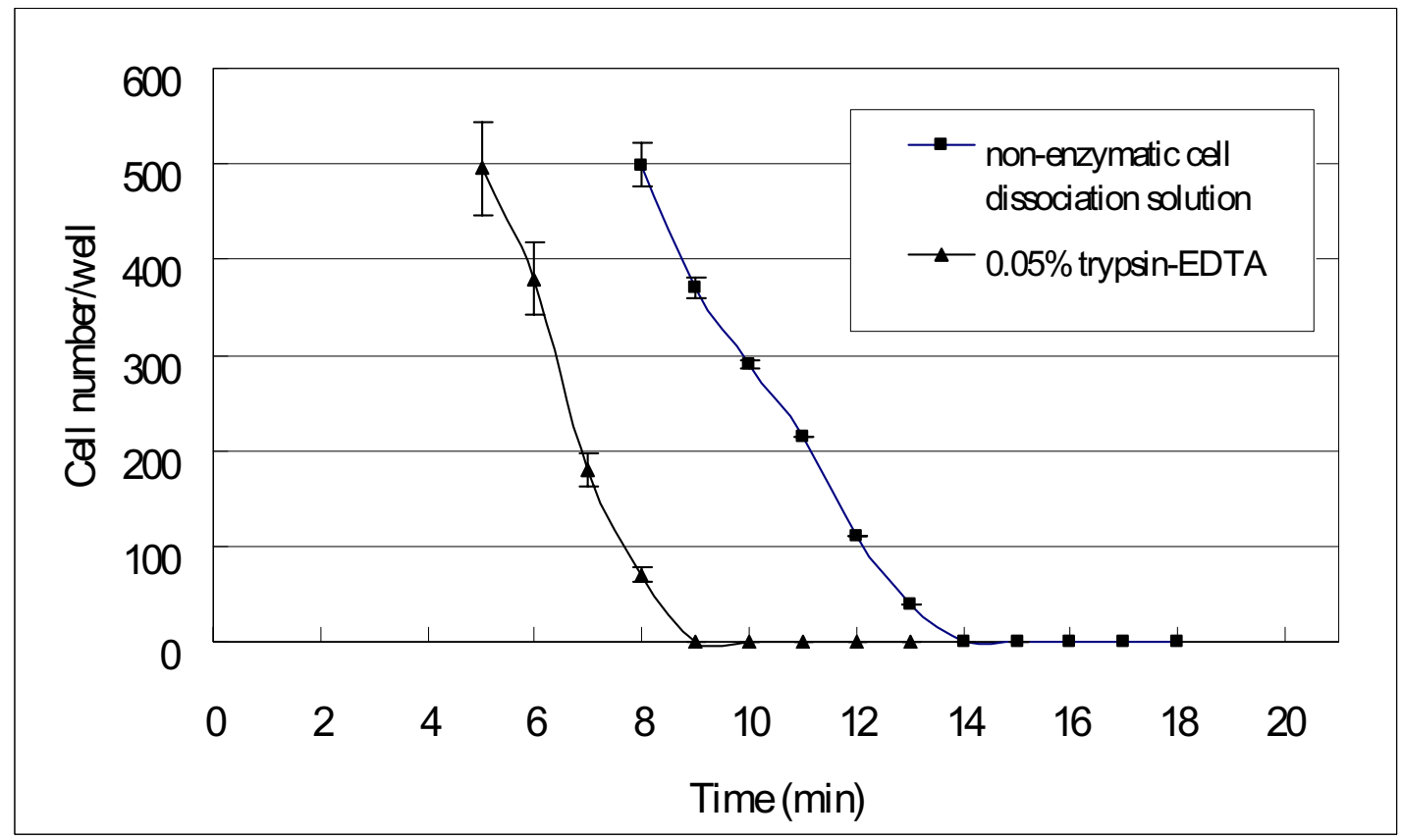

B

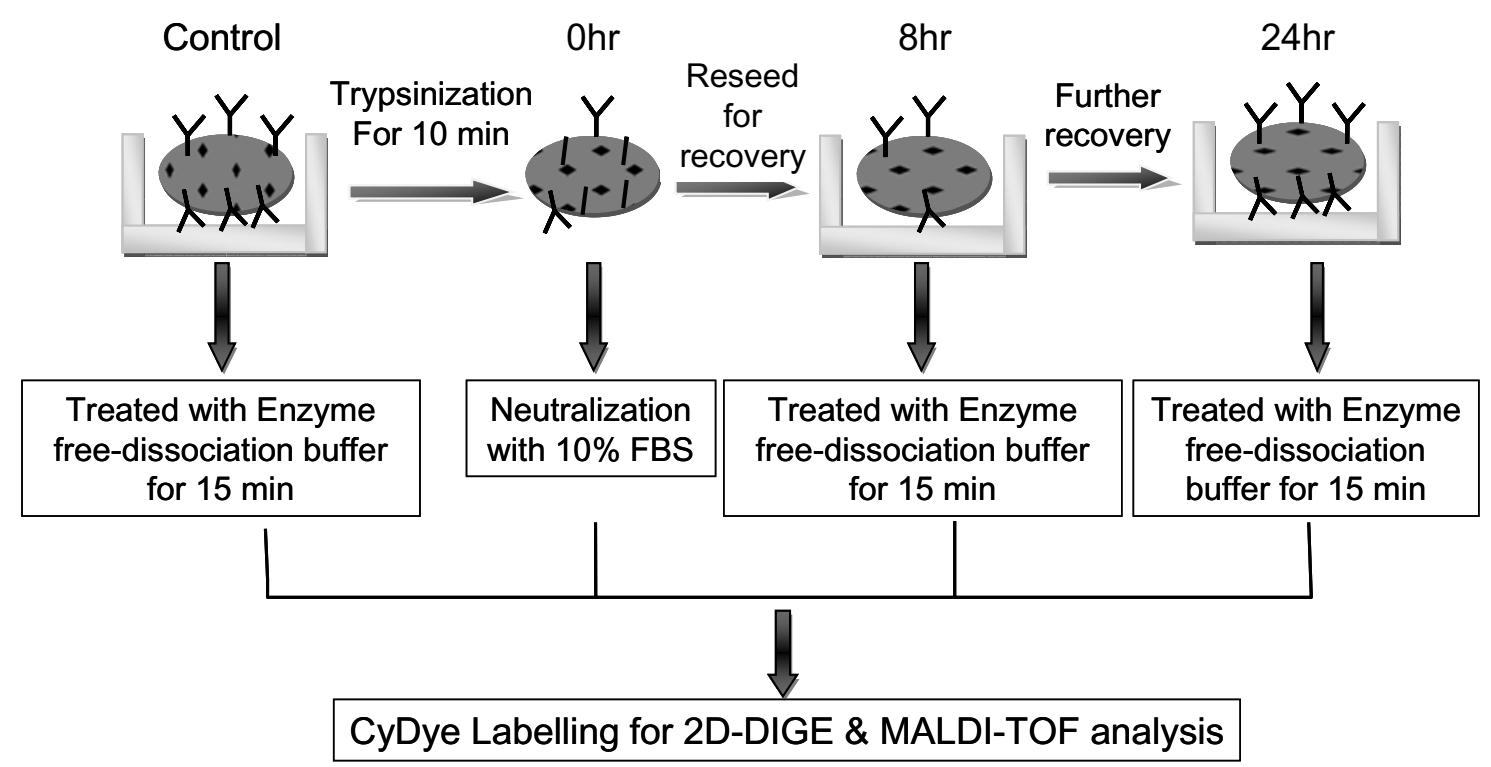

Figure 1 Cell dissociation workflow with and without trypsin digestion. (A) The dissociation time for attached MCF-7 cells were determined where $90 \%$ confluent cells in 96-well cell culture plates were gently washed with HBSS twice followed by treated with $100 \mu$ l of non-enzymatic cell dissociation solution or $0.05 \%$ trypsin-EDTA. After indicated treatment times, cells were gently washed with HBSS and the number of adherent cells counted. The mean cell number of 4 independent assays is shown +/-SD. (B) Overview of cell dissociation workflow with and without trypsin digestion of adhesive MCF-7 cells. 


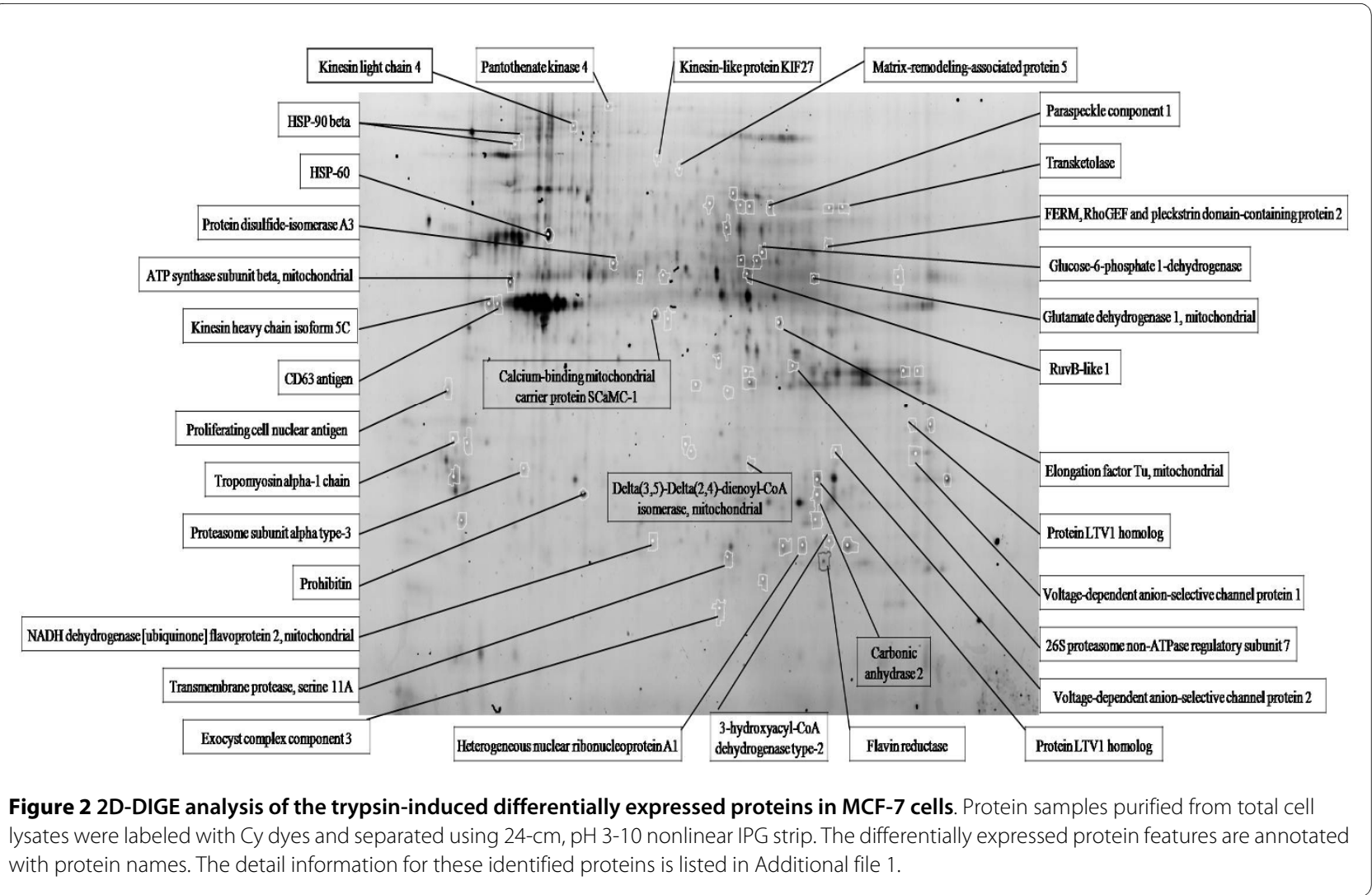

that more than 60 protein features were showing greater than 1.5-fold change in expression level. MALDI-TOF MS identification revealed that 36 proteins were differentially expressed during trypsinization (Figure 2 and Additional file 1). Most of these identified proteins are located in the cytoplasm (39\%), mitochondria (25\%) and the plasma membrane (22\%), and these proteins are found to be involved in growth regulation (23\%), metabolism (11\%) and vascular transportation (11\%).

\section{Validation of identified proteins by immunoblotting}

Immunoblot analysis was carried out to confirm the expression levels of the following differentially expressed proteins (tropomyosin alpha-1, HSP-60, SCaMC-1, VDAC2, VDAC1 and CD63) observed in 2D-DIGE (Figure 3). The immunoblotting validation indicated that tropomyosin alpha-1 and HSP-60 decreased at $0 \mathrm{hr}$ of trypsinization, but were restored after $24 \mathrm{hr}$. This result was consistent with the proteomic analysis. Protein expression levels of SCaMC-1 and CD63 were down-regulated and up-regulated, respectively at hour 8 after trypsinization, and their expression levels did not return to the control levels even after $24 \mathrm{hr}$. In another observation, both VDAC1 and VDAC2 were up-regulated at the time of trypsinization and recovered to basal level at around $24 \mathrm{hr}$ and $8 \mathrm{hr}$, respectively, which were both consistent with the 2D-DIGE results.

\section{Detection of trypsin-induced differential protein expression in cervical cancer cells}

It is interesting and important to know whether trypsineinduced protein alterations in MCF-7 cells are reproducible in other cell types. Accordingly, cervical adenocarcinoma Hela cells were used to examine protein expression changes by trypsinization (Figure 4). Immunoblotting analysis indicated that tropomyosin alpha-1 was slightly decreased at $0 \mathrm{hr}$ and $8 \mathrm{hr}$ of trypsinization and was slightly restored after $24 \mathrm{hr}$. In contrast, HSP-60 significantly decreased at $0 \mathrm{hr}$ of trypsinization and was completely restored after $24 \mathrm{hr}$. This result is consistent with the proteomic analysis found in MCF-7 cells. Protein expression level of SCaMC-1 was down-regulated soon after trypsinization, and the expression level did not return to the control level even after $24 \mathrm{hr}$. This implies SCaMC-1 may need a longer period of time for recovery and the result is highly consistent with the proteomic analysis found in MCF-7 cells. Furthermore, VDAC2 and CD63 were up-regulated at the time soon after trypsinization and at $24 \mathrm{hr}$, respectively; which is also consistent with the previous results found in MCF-7 cells. In contrast to an instantly up-regulated VDAC1 level was shown in MCF-7 cells, a significantly enhanced VDAC1 level in Hela cells starting from $8 \mathrm{hr}$. In summary, trypsinization-induced protein alterations in MCF-7 cells 


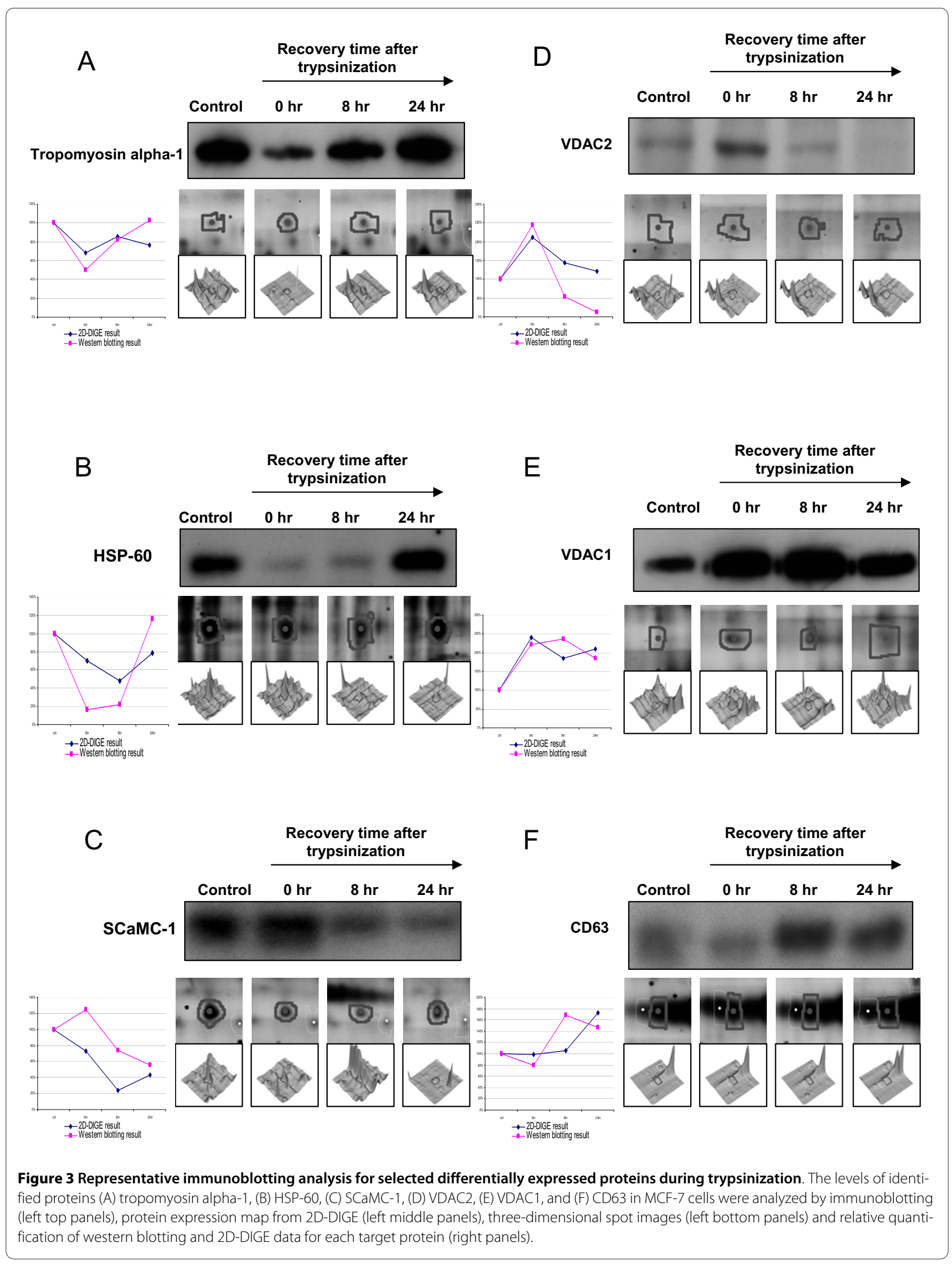




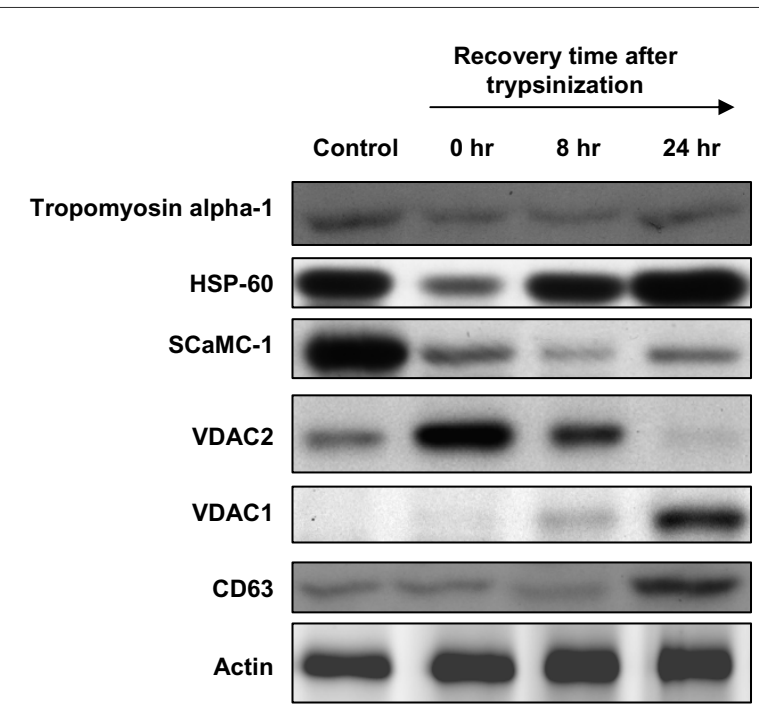

Figure 4 Expression level analysis of tropomyosin alpha-1, HSP60 , SCaMC-1, VDAC1, VDAC2 and CD63 during trypsinization in Hela cells.

are highly correlated to Hela cells except for Tropomyosin alpha-1 and VDAC1.

\section{Functional expression profiles of the identified differentially expressed proteins}

With the basis of a Swiss-Prot search and KEGG pathway analysis, numerous potential biological functions of the identified proteins in MCF-7 cells which were treated with trypsin and then recovered for $0 \mathrm{hr}, 8 \mathrm{hr}$ or $24 \mathrm{hr}$ or left untreated were determined. Proteins known to regulate cell metabolism, growth regulation, mitochondrial electron transportion and cell adhesion were found to be down-regulated in trypsinized MCF-7 cells even after a 24-hr recovery in fresh medium (Figure 5A, B, C and 5E). In contrast, proteins known to regulate cell apoptosis were shown to be up-regulated in trypsinized MCF-7 cells after a 24-hr recovery (Figure 5D). These proteomic results indicated that trypsinization might decrease growth- and metabolism-related protein expression levels and slightly increase apoptosis-related proteins. To further examine this observation, trypsin-induced cell signals in cell survival, apoptosis and cell cycle regulation were verified by immunoblotting. The result showed the cell survival marker, $\mathrm{Bcl}-2$, was down-regulated; on the other hand, the cell apoptotic marker, p53, and cell cycle inhibitor, p21, were both up-regulated during trypsinization (Figure 6).

\section{Discussion}

Differential protein expression in adhesive cell subculture with trypsin has not been discussed thoroughly in previous studies. However, due to the proteolytic activity of trypsin, membrane proteins of the cell might be damaged which results in cellular dysfunctions. Hence, a CyDye labeling 2D-DIGE technique, along with MALDI-TOF MS identification, was performed in this study, and 36 proteins revealed a significant expression change due to trypsinization. Moreover, the proteomic results demonstrated that trypsinization down-regulated growth- and metabolism-related protein expressions and up-regulated apoptosis-related protein expressions. These findings implied that trypsin used for cell subculture had a remarkable adverse effect on cell physiology. Notably, some of these trypsin-induced differentially expressed proteins were reversible while a portion of these proteins remains dysregulated even after a $24-\mathrm{hr}$ recovery in fresh medium.

Proteomic analysis of the trypsin-induced differentially expressed proteins in MCF-7 indicated that numerous differentially expressed proteins are involved in the chaperon functions (HSP-60, HSP-90 beta, Protein disulfideisomerase A3) implying trypsinization might induce a stress response on culture cells. These chaperon proteins have been reported to be cell surface located [14-16] and cell surface located chaperons also play crucial roles in mediating integrin activations in breast cancer cells [17]. In addition, one of the most important findings in this study is that trypsinization decreases the growth- and metabolism-related protein expression levels and increases the apoptosis-related protein expression levels. This observation is not only confirmed by the immunoblotting result (Figure 6), but also verified by MALDI-TOF, which indicate that trypsinization decreases the expression levels of proteins involved in DNA replication (Proliferating cell nuclear antigen and RuvB-like 1), RNA splicing (Heterogeneous nuclear ribonucleoprotein A1 and Heterogeneous nuclear ribonucleoproteins A2/B1) and mitochondria metabolism (3-hydroxyacyl-CoA dehydrogenase type-2, ATP synthase subunit beta, Calcium-binding mitochondrial carrier protein SCaMC-1, Delta(3,5)-Delta(2,4)-dienoyl-CoA isomerase, Glutamate dehydrogenase 1 and NADH dehydrogenase). In contrast, trypsinization promotes the overexpression of voltage-dependent anion-selective channel protein 1 and voltage-dependent anion-selective channel protein 2 . These proteins play essential roles in the increase of mitochondrial membrane permeability and lead to cell apoptosis [18] (Figure 5 and Additional file 1). Importantly, it is essential to know whether the trypsinizationinduced protein alterations in MCF-7 cells are commonly recognized in other cell types. Therefore, the other cell line, Hela cell was used for further investigation and the results showed that trypsinization-induced protein alterations in MCF-7 cells are mostly comparable in Hela cells.

In conclusion, 2D-DIGE based proteomics analysis serves as a useful tool to monitor trypsin-induced cell 
A

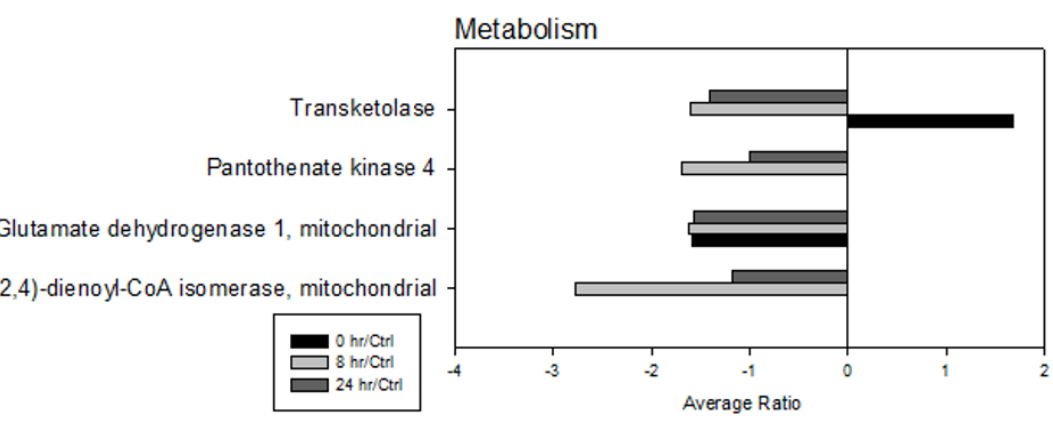

B

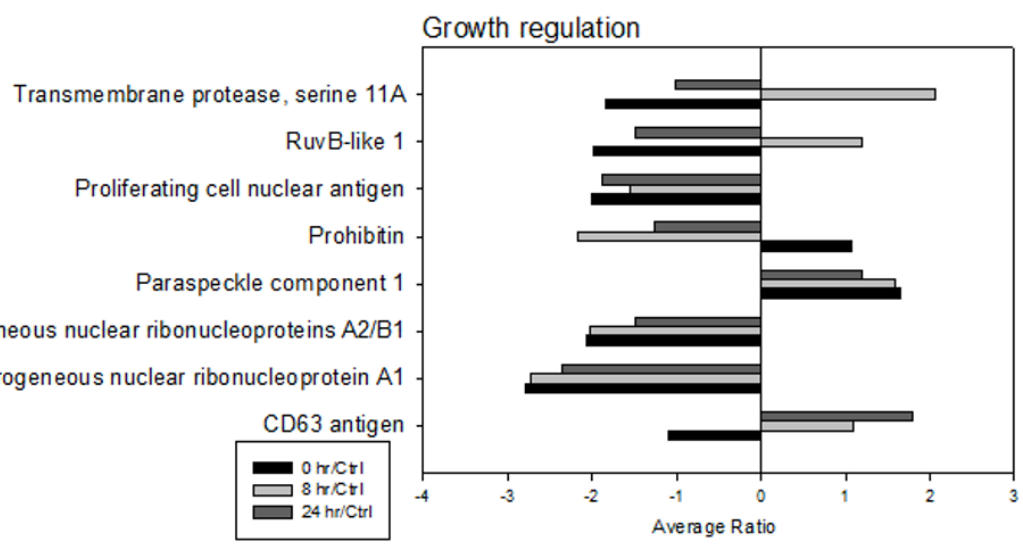

C

Electron transport

JH dehydrogenase [ubiquinone] flavoprote in 2, mitochondrial

ATP synthase su bunit beta, mitochondrial
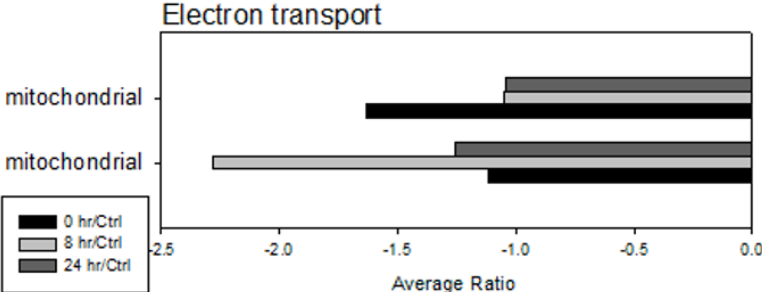

D

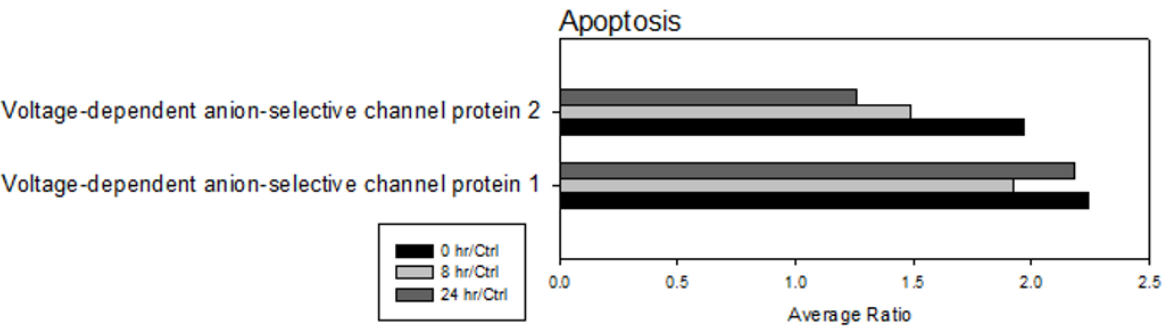

E

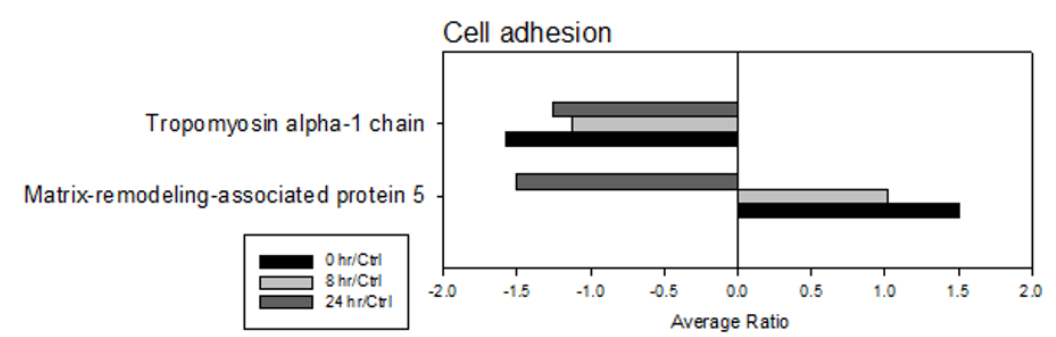

Figure 5 Expression profiles for proteins potentially contributing to (A) metabolism (B) growth regulation (C) electron transportation (D) apoptosis (E) cell adhesion in comparing MCF-7 cells treated with $0.05 \%$ trypsin for 10 min followed by recovery for $0 \mathrm{hr}, 8 \mathrm{hr}$ and $24 \mathrm{hr}$ or left untreated. The horizontal bars represent fold change in protein expression and the vertical axis indicates the identified proteins. Additional details for each protein can be found in Additional file 1. 


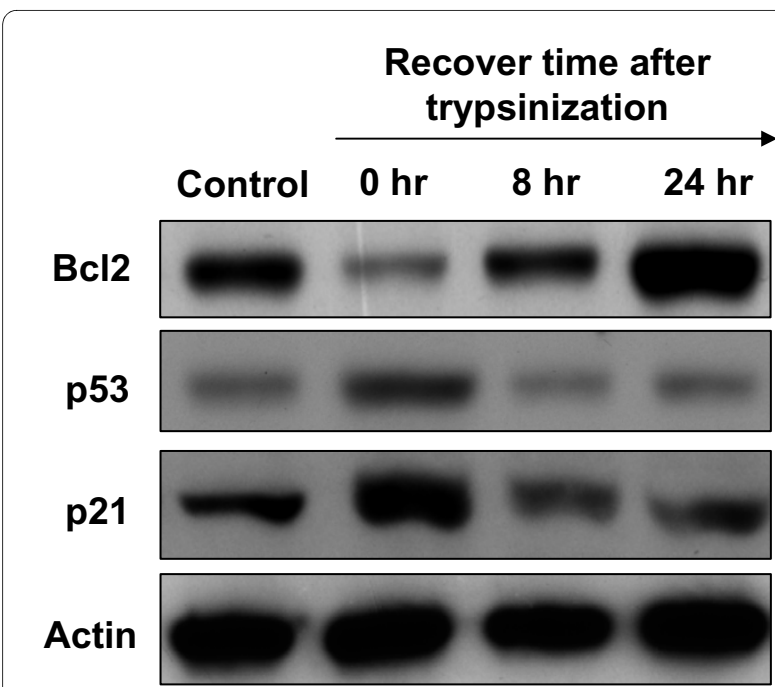

Figure 6 Comparison of trypsin-induced cell signaling in cell survival, apoptosis and cell cycle regulation. Activation of survival, apoptosis and cell cycle inhibition signalling pathways were analyzed by immunoblotting with anti-Bcl2, anti-p53 and anti-p21 antibodies, respectively.

proteome alterations in this study. Trypsinization has shown to down-regulate growth- and metabolism-related protein expression and up-regulate apoptosis-related protein expression. This study helps researchers who work in the cell signaling and cell biology fields to carefully examine the impact of trypsin in carrying out their experimental design.

\section{Additional material}

Additional file 1 Alphabetical list of trypsin digestion-induced differentially expressed proteins identified by MALDI-TOF peptide mass fingerprinting after 2D-DIGE analysis. anot analyzed; bsubcellular location and functional classification of identified proteins were referred to the Uniprot website http://www.uniprot.org/.

\section{Abbreviations}

1-DE: one-dimensional gel electrophoresis; 2-DE: two-dimensional gel electrophoresis; Ab: antibody; AmBic: ammonium bicarbonate; CCB: colloidal coomassie blue; CHAPS: 3- [(3-cholamidopropyl)-dimethylammonio]-1propanesulfonate); DIGE: differential gel electrophoresis; DTT: dithiothreitol; FCS: fetal calf serum; IAM: iodoacetamide; MALDI-TOF MS: matrix assisted laser desorption ionization-time of flight mass spectrometry; TFA: trifluoroacetic acid.

\section{Competing interests}

The authors declare that they have no competing interests.

\section{Authors' contributions}

$H L C$ and $H C C$ designed the experiments and the draft manuscript writing. HLH, HWH, TCL, YWC, CLW, YCL, STL performed the cell culture, 2D-gel electrophoresis, image analysis and immunoblotting. HLC and HCC supervised the experiments and the data analysis. TRL, PCL, CWL, CHL, HTC contributed to the data interpretation and the data discussion. HLC, HTC and HCC finalized the manuscript. All authors have read and approved the final manuscript.

\section{Acknowledgements}

This work was supported by grant NSC 97-2311-B-007-005 from the National Science Council, Taiwan, grant CMU-NTHU Joint Research No.98N2443E1 and grant VGHUST98-P5-15 \& VGHUST99-P5-22 Veteran General Hospitals University System of Taiwan Joint Research Program. The authors thank the assistance of Dr Cheng-Chin Kuo (National Health Research Institute) for DIGE image scanning support.

\section{Author Details}

1Institute of Bioinformatics and Structural Biology \& Department of Life Sciences, National Tsing Hua University, Hsinchu, Taiwan, 2Department of Medical Laboratory Science and Biotechnology, China Medical University, Taichung, Taiwan, ${ }^{3}$ Department of Microbiology, School of Medicine, China Medical University, Taichung, Taiwan, ${ }^{4}$ Graduate Institute of Molecular Systems Biomedicine, China Medical University, Taichung, Taiwan and ${ }^{5}$ Department of Applied Science, National Hsinchu University of Education, Hsinchu, Taiwan

Received: 19 March 2010 Accepted: 11 May 2010

Published: 11 May 2010

\section{References}

1. Peralta SA, Knudsen KA, Tecson-Miguel A, McBrearty FX, Han AC, Salazar H: Expression of $\mathrm{E}$-cadherin and $\mathrm{N}$-cadherin in surface epithelial-stromal tumors of the ovary distinguishes mucinous from serous and endometrioid tumors. Hum Pathol 1997, 28:734-739.

2. Rosivatz E, Becker I, Bamba M, Schott C, Diebold J, Mayr D, Hofler H, Becker $\mathrm{KF}$ : Neoexpression of $\mathrm{N}$-cadherin in $\mathrm{E}$-cadherin positive colon cancers. Int J Cancer 2004, 111:711-719.

3. Kuphal S, Bosserhoff AK: Influence of the cytoplasmic domain of Ecadherin on endogenous $\mathrm{N}$-cadherin expression in malignant melanoma. Oncogene 2006, 25:248-259.

4. Lee JW, Soung YH, Kim SY, Park WS, Nam SW, Kim SH, Lee JY, Yoo NJ, Lee SH: ERBB2 kinase domain mutation in a gastric cancer metastasis. APMIS 2005, 113:683-687.

5. Bekaii-Saab T, Williams N, Plass C, Calero MV, Eng C: A novel mutation in the tyrosine kinase domain of ERBB2 in hepatocellular carcinoma. BMC Cancer 2006, 6:278.

6. Timms JF, Cramer R: Difference gel electrophoresis. Proteomics 2008, 8:4886-4897.

7. Westermeier R, Scheibe B: Difference gel electrophoresis based on lys/ cys tagging. Methods Mol Biol 2008, 424:73-85.

8. Marouga R, David S, Hawkins E: The development of the DIGE system: 2D fluorescence difference gel analysis technology. Anal Bioanal Chem 2005, 382:669-678.

9. Lai TC, Chou HC, Chen YW, Lee TR, Chan HT, Shen HH, Lee WT, Lin ST, Lu YC, Wu CL, Chan HL: Secretomic and Proteomic Analysis of Potential Breast Cancer Markers by Two-Dimensional Differential Gel Electrophoresis. J Proteome Res 2010, 9:1302-1322.

10. Chou HC, Chen YW, Lee TR, Wu FS, Chan HT, Lyu PC, Timms JF, Chan HL: Proteomics study of oxidative stress and Src kinase inhibition in $\mathrm{H} 9 \mathrm{C} 2$ cardiomyocytes: A cell model of heart ischemia reperfusion injury and treatment. Free Radic Biol Med 2010 in press.

11. Chan HL, Gaffney PR, Waterfield MD, Anderle H, Peter MH, Schwarz HP, Turecek PL, Timms JF: Proteomic analysis of UVC irradiation-induced damage of plasma proteins: Serum amyloid P component as a major target of photolysis. FEBS Lett 2006, 580:3229-3236.

12. Chan HL, Gharbi S, Gaffney PR, Cramer R, Waterfield MD, Timms JF: Proteomic analysis of redox- and ErbB2-dependent changes in mammary luminal epithelial cells using cysteine- and lysine-labelling two-dimensional difference gel electrophoresis. Proteomics 2005, 5:2908-2926.

13. Chan HL, Chou HC, Duran M, Gruenewald J, Waterfield MD, Ridley A, Timms JF: Major role of EGFR and SRC kinases in promoting oxidative stress-dependent loss of adhesion and apoptosis in epithelial cells. $J$ Biol Chem 2009, 285:4307-4318.

14. Shin BK, Wang H, Yim AM, Le Naour F, Brichory F, Jang JH, Zhao R, Puravs E, Tra J, Michael CW, Misek DE, Hanash SM: Global profiling of the cell surface proteome of cancer cells uncovers an abundance of proteins with chaperone function. J Biol Chem 2003, 278:7607-7616. 
15. Jang $\mathrm{JH}$, Hanash S: Profiling of the cell surface proteome. Proteomics 2003, 3:1947-1954.

16. Mayrhofer C, Krieger S, Allmaier G, Kerjaschki D: DIGE compatible labelling of surface proteins on vital cells in vitro and in vivo. Proteomics 2006, 6:579-585.

17. Barazi HO, Zhou L, Templeton NS, Krutzsch HC, Roberts DD: Identification of heat shock protein 60 as a molecular mediator of alpha 3 beta 1 integrin activation. Cancer Res 2002, 62:1541-1548.

18. Tsujimoto Y, Shimizu S: The voltage-dependent anion channel: an essential player in apoptosis. Biochimie 2002, 84:187-193.

\section{doi: 10.1186/1423-0127-17-36}

Cite this article as: Huang et al., Trypsin-induced proteome alteration during cell subculture in mammalian cells Journal of Biomedical Science 2010, $17: 36$

Submit your next manuscript to BioMed Central and take full advantage of:

- Convenient online submission

- Thorough peer review

- No space constraints or color figure charges

- Immediate publication on acceptance

- Inclusion in PubMed, CAS, Scopus and Google Scholar

- Research which is freely available for redistribution

Submit your manuscript at www.biomedcentral.com/submit
() BioMed Central 